\title{
A LEITURA AO CENTRO: como promover a literacia da leitura na escola
}

\author{
PAULO M. FARIA
}

Doutor em Ciências da Educação, Tecnologia Educativa pela Universidade do Minho, Portugal.

Desenvolve o seu pos-doc na área da leitura digital. Desempenha Coordenador Cientifico-

Pedagógico, Centro de Língua Portuguesa - Universidade Nacional de Timor Lorosa'e ao serviço do

Camões, I.P. ORCID: https://orcid.org/0000-0001-8232-4815. E-mail: pauloprofe@gmail.com

\begin{abstract}
ÁDILA FARIA
Doutora em Estudos da Criança, Tecnologias de Informação e Comunicação pela Universidade do Minho, Portugal. Integra vários grupos internacionais de pesquisa, como COST - Digital Literacy and Multimodal Practices of Young Children (DigiLitEY). Desempenha o cargo de Professora Bibliotecária. ORCID: https://orcid.org/0000-0002-5550-800X. E-mail: adifaria@gmail.com
\end{abstract}

\section{ALTINA RAMOS}

Doutora em Estudos da Criança, Tecnologias de Informação e Comunicação pela Universidade do Minho, Portugal. Professora Auxiliar no Departamento de Estudos Curriculares e Tecnologia

Educativa da Universidade do Minho. Investigadora associada ao Centro de Investigação em

Educação. ORCID: https://orcid.org/000-0002-5668-4304. E-mail: altina@ie.uminho.pt 


\section{A LEITURA AO CENTRO: Como promover a literacia da leitura na escola}

Tendo presente a centralidade da língua como instrumento basilar na economia curricular, destacou-se a leitura como competência basilar, não só no acesso ao saber, mas também na fruição estética, desde o primeiro ciclo até ao final do ensino secundário. Este artigo expõe e reflete acerca do trabalho dos autores, ao longo de mais de uma década, na busca de responder à baixa proficiência leitora evidenciada pelos alunos face a textos informativos e literários. Ao mesmo tempo, são analisadas propostas centradas no âmbito da literacia da leitura, sempre numa perspetiva multimodal de promoção do código linguístico tendo presente as profundas transformações comunicacionais patentes no acesso à informação no contexto da sociedade digital. Apresenta-se, em primeiro lugar uma abordagem multidisciplinar a partir da obra a Maior Flor do Mundo de José Saramago; seguidamente, detalham-se partes mais relevantes que uniram tecnologias digitais no desenvolvimento da leitura, através do blogue Língua Portuguesa e, paralelamente, de uma rede social: o blogue, para um trabalho mais centrado na prática pedagógica; a rede social, para estimular a leitura livre e a partilha dessas experiências de leitura informal. Por último, surgiu o projeto biblioteca digital que consistiu no desenvolvimento de várias ações de acesso e promoção da leitura. A evidência recolhida através de observação do trabalho diário e dos dados relativos ao aumento do nível de proficiência leitora, revelam que estes ambientes de leitura digital, articulados com outras iniciativas de carácter multimodal, têm trazido benefícios académicos, sociais e pessoais aos alunos das escolas.

Palavras Chaves: Leitura. Literacia. Literatura. Redes. Digital.

\section{READING TO THE CENTER: how to promote reading's literacy at school}

Bearing in mind the centrality of language as a pivotal tool in curricular economics, in the same way, reading was the pivotal competence, not only in access to knowledge but also in aesthetic enjoyment, from the first cycle until the end of secondary education. This article exposes and reflects on the authors' work over more than a decade in the search to respond to the low reading proficiency evidenced by the students in relation to informative and literary texts. At the same time, proposals centered on reading literacy are been going through analysis, always with a multimodal perspective of promoting the language code, bearing in mind the profound communicative transformations that are evident in the access to information in the context of the digital society. It presents, firstly a multidisciplinary approach from the work of José Saramago's Greatest Flower in the World; next, arises the most relevant parts that link digital technologies in the development of reading, through the blog Portuguese Language and, in parallel, of a social network: the blog, for a more focused work in pedagogical practice; the social network, to encourage free reading and sharing of these informal reading experiences. Finally, a digital library project was developed, which consisted in the development of several actions to access and promote reading. The evidence gathered through the observation of daily work and the data related to the increase in the level of reading proficiency reveal that these digital reading environments articulated with other initiatives of a multimodal nature, have brought the academic, social and personal benefits to the students of these schools.

Key-words: Reading. Literacy. Literature. Networks. Digital. 


\section{LEER EL CENTRO: cómo promover la alfabetización en la escuela}

Teniendo en cuenta la centralidad del lenguaje como instrumento básico en la economía curricular, la lectura se destacó como una competencia básica, no solo en el acceso al conocimiento, sino también en el disfrute estético, desde el primer ciclo hasta el final de la educación secundaria. Este artículo expone y reflexiona sobre el trabajo de los autores, durante más de una década, buscando responder a la baja competencia en lectura que evidencian los estudiantes en relación con los textos informativos y literarios. Al mismo tiempo, las propuestas se centran en la alfabetización lectora, siempre con una perspectiva multimodal para promover el código de idioma, teniendo en cuenta las profundas transformaciones comunicativas que se evidencian en el acceso a la información en el contexto de la sociedad digital. Presenta, en primer lugar, un enfoque multidisciplinario del trabajo de La flor más grande del mundo de José Saramago; A continuación, las partes más relevantes que vinculan las tecnologías digitales en el desarrollo de la lectura, a través del blog Portuguese Language y, en paralelo, de una red social: el blog, para un trabajo más enfocado en la práctica pedagógica. La red social, para fomentar la lectura gratuita y el intercambio de estas experiencias de lectura informal. Finalmente, se desarrolló el proyecto de biblioteca digital, que consistió en el desarrollo de varias acciones para acceder y promover la lectura. La evidencia recopilada a través de la observación del trabajo diario y los datos sobre el aumento de la capacidad de lectura revela que estos entornos de lectura digital, junto con otras iniciativas multimodales, han brindado beneficios académicos, sociales y personales a los alumnos de las escuelas.

Palabras claves: Lectura. Alfabetización. Literatura. Redes. Digital. 


\section{A LEITURAAO CENTRO: como promover a literacia da leitura na escola}

\section{Preâmbulo}

Na última década, os autores deste artigo têm investigado e realizado um trabalho efetivo em todos os graus de ensino em torno da promoção da literacia da leitura. Ora, como sustenta a investigação, ensinar e aprender extravasa os pressupostos grafocêntricos herdados de Gutenberg (WARSCHAUER ET AL., 2010). Na verdade, atualmente, a literacia da leitura inclui o uso, reflexão e compreensão de textos multimodais, cujo domínio de diferentes formas de expressão e o desenvolvimento de competências orais, escritas e multimédia, devem ser consideradas. Perante omnipresença das tecnologias digitais que transformam o tempo, os espaços e a forma como hoje se comunica e interage, o desafio de perspetivar a leitura num quadro de ações que promovam a comunicação, a exploração de conteúdos de e situações para responder aos seus gostos, interesses e necessidades, será apresentado nos exemplos que se seguem.

$\mathrm{Na}$ abertura deste texto, convêm assegurar que nas ações a seguir explicitadas está subjacente uma lógica de reconfiguração que procurou uma nova abordagem ao nível pedagógico e didático e que passou pelo recurso à construção de cenários educativos inovadores com uso de tecnologias digitais. Assume-se que a relação com a leitura, e genericamente com o ensino do Português na primeira década do séc. XXI, exige re-desenhar um conjunto de estratégias com diferenças substanciais relativamente a um passado ainda que recente. Não é, pois, possível ignorar que na projeção no processo de aprendizagem do idioma, das ferramentas e das linguagens facultadas pelas chamadas tecnologias da informação e comunicação, associadas a procedimentos de escrita e de leitura de textos eletrónicos e à disseminação da Internet e das comunicações em rede, constitua um exemplo fragrante de oportunidades singulares e, ao mesmo tempo, de desafios significativos a que era imperioso responder (BARRON, 2006; COLLINS ET AL., 2010; CRAWFORD, ET AL., 2009; KUMAR ET AL, 2011; ROSE ET AL., 2009; WOOD, 2006). Se a revolução digital (GREEN, 2010), tem implicações positivas na educação, é urgente exigir dos professores que reaprendam a ensinar, assumindo as profundas mudanças (HILL ET AL., 2001; LI ET AL., 2010) de uma sociedade que vive em rede e à escala planetária, sabendo operacionalizá-las na sua prática pedagógica. 


\section{Síntese das ações/projetos}

\section{Biblioteca que estás na nuvem, na sala de aula e em cada um de nós}

O cenário de aprendizagem intitulado "Biblioteca que estás na nuvem, na sala de aula e em cada um de nós", que se projetou especificamente para a realidade escolar de uma escola, a partir da problemática anteriormente enunciada no preâmbulo, representa uma experiência pedagógica de articulação curricular entre Matemática e outras áreas do saber, desenvolvida com alunos do primeiro ciclo e alunos do ensino secundário.

O objetivo passava por construir um Cenário de Aprendizagem seguindo as tendências da New Media Consortium e baseada nas orientações da European Schoolnet, através da caixa de ferramentas do projeto Future Classroom Lab da EUN (http://www.eun.org/professionaldevelopment/future-classroom-lab). Implicava, em primeiro lugar, refletirmos sobre os principais desafios e tendências relevantes da sociedade, da educação e da tecnologia emergente com impacto sobre o ensino e a aprendizagem, sobre a prática dos professores, sobre os alunos e também sobre o nível de maturidade das escolas relativamente à utilização das TIC no ensino e na aprendizagem. Neste pressuposto, foi constituído um grupo de pessoas a que designamos por grupo central do processo de inovação. Era necessário arquitetar uma visão que implicasse todo o ecossistema educativo numa missão conjunta e global dos atores educativos de uma escola. Nas palavras de Dias de Figueiredo (2016), deverá ser repensar a escola para além do digital. Assim, fizeram parte desse grupo elementos da direção, professores do primeiro ciclo e ensino secundário para que todos pudessem contribuir com ideias e perspetivas sobre mudanças e inovação para a escola.

Partiu-se para um debate alargado com o grupo e que nos forneceu pistas para criar uma visão da educação que serviu para impulsionar a mudança e a inovação na nossa escola. Neste processo, utilizamos algumas aplicações de votação online (como por exemplo, Tricider. com) como recurso colaborativo para priorizar as tendências emergentes pretendidas para a escola, relacionadas com a tecnologia educativa e a transformação da educação. Deste debate, resultaram três possíveis tendências a seguir: aprendizagem colaborativa, STEAM e utilização dos dispositivos móveis.

É, partindo da obra de educação literária A maior flor do mundo, de José Saramago, que procuramos criar um cenário de aprendizagem que contribuísse para o desenvolvimento de competências, valores e princípios em linha com o que é hoje solicitado, com o objetivo de consolidar as aprendizagens presentes no currículo, mas também nos valores e princípios

\footnotetext{
p/U] ails Salvador, v. 4, n. 2, p. 26-46, mai./ago. 2019
} 
sinalizados no Perfil do Aluno (MARTINS ET AL., 2017). O objetivo central passava, então, por relacionar o Referencial Aprender com a Biblioteca Escolar (CONDE ET AL., 2012), os programas e as metas curriculares no âmbito de uma formação global para o desenvolvimento de literacias numa perspetiva de complementaridade entre os descritores previstos e as várias áreas curriculares.

Alicerçados na obra de educação literária "A Maior Flor do Mundo", de José Saramago, num trabalho articulado entre a biblioteca escolar, uma turma do $4 .^{\circ}$ ano e uma turma do $10 .^{\circ}$ de matemática, fez-se a leitura coletiva e a exploração individual e colaborativa, com recurso a metodologias e recursos inovadores, para averiguar a presença da matemática nas suas múltiplas representações: imagens, palavras e textos.

Toda a planificação e exploração da obra recorreram à utilização dos meios digitais que permitem ler melhor, interpretar, apreciar o texto literário e reconhecer valores culturais, éticos e estéticos evidenciados na obra e cruzá-los, em simultâneo, através de um conjunto de problemas matemáticos suscitados na leitura transdisciplinar. Os alunos envolveram-se em trabalhos de exploração e investigação, aliando os conhecimentos científicos na resolução de problemas matemáticos, promovendo o diálogo no sentido de se aprofundar uma cultura de colaboração e interdependência, tendo presente a articulação de objetivos e valores educativos entre as várias disciplinas implicadas. Os alunos mais novos selecionaram informação e formularam questões/problemas matemáticos para as quais podiam não ter respostas científicas. Recorreram, depois, aos colegas mais velhos para os ajudarem a compreender cientificamente os problemas que levantaram. Por sua vez, estes assumiram o papel de pesquisadores e investigadores e, em grupos, procuraram responder aos conteúdos matemáticos enquadrados nos temas e conteúdos aprendidos.

Professores e alunos assumem um novo papel. A abordagem pedagógica dos professores baseia-se numa aprendizagem de trabalho de projeto, seguindo uma perspetiva de aprendizagem ativa, tecnológica, interativa e globalizante, onde os processos de decisão, organização e resolução de problemas implicam todos os envolvidos. O professor está presente em processo negocial, monitorizando e tomando decisões. No âmbito da disciplina de Matemática, com os alunos de ensino secundário, implementou-se uma metodologia baseada na resolução de problemas, numa dinâmica colaborativa que fez uso dos seus dispositivos móveis e apps, como estratégia de ensino aprendizagem. Num contexto de ambientes educativos inovadores, de mudança de práticas educativas em sala de aula, esta abordagem pedagógica prevê a utilização de forma eficaz das competências digitais, a autonomia, responsabilidade e autorregulação da aprendizagem 
dos alunos, e consequentemente, maior motivação para o trabalho escolar. Nesta perspetiva, o professor assume o papel de facilitador na construção de conhecimento.

Os objetivos da avaliação e da aprendizagem contemplaram uma perspetiva que passava por utilizar e dominar instrumentos diversificados para pesquisar, descrever, avaliar, validar e mobilizar informação de forma crítica e autónoma, verificando diferentes fontes documentais e a sua credibilidade; pensar de modo abrangente e em profundidade, de forma lógica, observando, analisando informação, experiências ou ideias, argumentando com recurso a critérios implícitos ou explícitos, com vista à tomada de posição fundamentada e adequar comportamentos em contextos de cooperação, partilha e colaboração.

Havia que desafiar a reinvenção da escola pelo desenho em novas interfaces, ultrapassando uma abordagem "monolithic" (SCOTT-WEBBER ET AL., 2014, p. 8) no exercício de ensinar; implicando, neste passo, ultrapassar um modelo de didático praticamente restrito ao manual, ou mesmo na sua projeção digital, processo aparentemente inovador, mas em boa verdade, perpetua modelos de pedagógicos datados no período pré-industrial.

Pensamos que o desafio deve ser colocado na arquitetura, no desenho de uma biblioteca que se integre num ecossistema que, na perspetiva de Leahy (2016), quando se refere à sala de aula, deve articular ao mesmo tempo três elementos: o espaço (que não se restringe ao espaço físico), a pedagogia e a tecnologia. É certo que a nível conceptual, estes elementos merecem uma consideração individual; porém, a coerência do design só terá consistência numa visão posicionada sempre a partir de uma matriz que não os desvalorize em nenhuma das ações a dinamizar.

Com efeito, deslocar a centralidade de todo o processo de ensino e aprendizagem focada nos alunos, foi o caminho mais adequado para fazer evoluir este cenário "Biblioteca que estás na nuvem, na sala de aula e em cada um de nós".

Descreve-se, de seguida, a primeira atividade de aprendizagem de articulação curricular desenvolvidas com os alunos, referindo os benefícios inerentes à participação e interação dos alunos neste projeto. Estas atividades descrevem muitas das interações realizadas com os alunos pormenorizando as ideias das abordagens inovadoras preconizadas para o cenário de aprendizagem. A sequência em que as atividades de aprendizagem foram implementadas, e a forma como se interrelacionaram, deram origem a uma "História de Aprendizagem" capaz de relatar a experiência vivenciada. 
a) Partilhar e colaborar através de um mural

Elegemos o mural Padlet.com pela facilidade de utilização, de comunicação e autonomia permitida aos alunos, tendo em conta a faixa etária a que se destinava - alunos do $10^{\circ}$ ciclo e ensino secundário. Pretendíamos manter um meio de comunicação, partilha e colaboração entre os alunos e os professores. Assim, alunos e professores tiveram acesso ao mural comum que serviu também para registo das respostas e dos materiais educativos/tutoriais (em formato vídeo, imagem e texto) produzidos mais tarde pelos alunos do $10^{\circ}$ ano. Os alunos mais novos acediam ao mural a partir da conta de email da biblioteca e os mais velhos acediam através das suas contas pessoais de email, o que facilitava o acesso e a partilha de conteúdos, enquadrados na temática, conferindo-lhe um maior protagonismo nas suas ações ao "publicar os seus trabalhos realizados na aula e a desenvolver projetos colaborativos" (MOURA, 2016, p. 8). Na organização do nosso mural de aprendizagem colaborativo, criámos vários separadores e tópicos para contextualização e orientação do trabalho pretendido, conforme se pode observar na Figura 1.

Figura 1. Padlet: Mural colaborativo de aprendizagem.

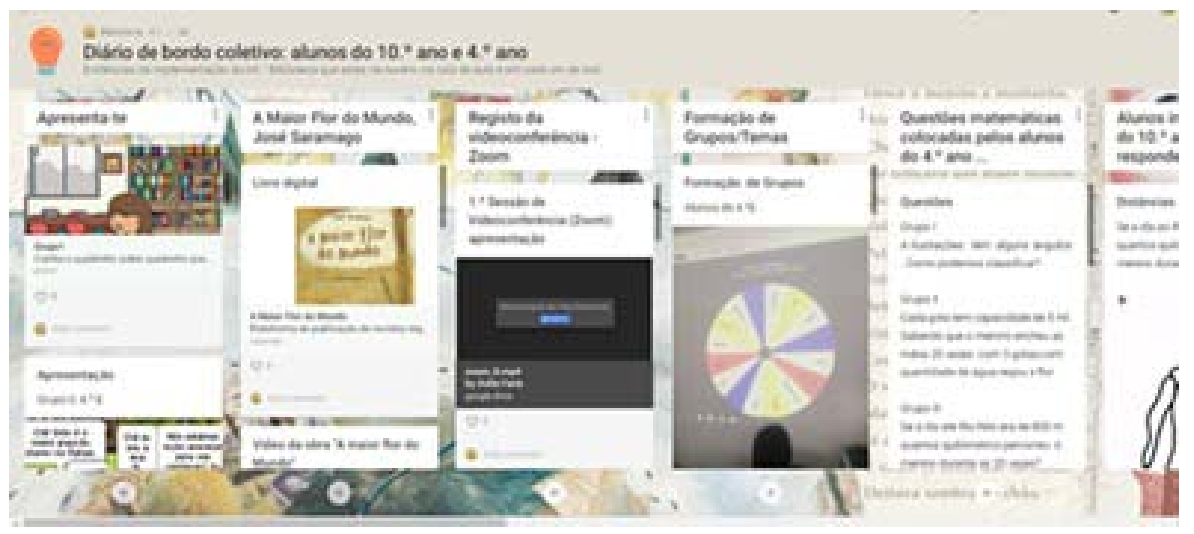

Fonte: https://padlet.com/bibliogilmonde/Portmat

\section{Ações e projetos no âmbito da promoção da literacia da leitura}

a) O blogue Lingua Portuguesa e a rede social bookcrossing EBI

Embora o blogue Língua Portuguesa (https://paulofaria.wordpress.com/) só tivesse entrado em funcionamento no mês de fevereiro de 2007, o trabalho de preparação começou logo no início do ano letivo de 2006/2007. 
O blogue, na altura, representava um dos recursos que permitia operacionalizar o conceito de interação online, que, segundo Granieri (2006, p. 31), era

(...) a mais acessível e natural das ferramentas destinados à partilha e à publicação - para além do texto, as imagens, os filmes e o som, que progressivamente, com o aumento da velocidade de transmissão dos dados, serão cada vez mais difundidos.

A utilização do blogue, como recurso, estratégia pedagógica ou com outras valências, começou a ser muito frequente em todos os níveis de ensino (Gomes, 2005).

O blogue Língua Portuguesa que esteve ativo até 2008/09 e continua consultável, foi criado na tentativa de reinventar a aula de Língua Portuguesa e de a tornar um espaço reflexivo quanto à utilização da língua nos seus diversos registos e modalidades. Face à emergência de novas literacias, esse projeto implicou uma reorientação das dinâmicas na sala de aula, o que exigiu um elevado investimento pessoal e profissional do professor mas também dos alunos. Com o passar do tempo, a planificação didática, as estratégias e os métodos foram revistos em consequência das novas práticas que se iam construindo com recurso às TIC. Porém, mantinha sempre presente que o foco de atuação passaria por motivar os alunos e despertá-los para níveis de interação mais intensos e autênticos, naturalmente conducentes a graus de mestria linguística tendencialmente mais ricos e complexos. De salientar a intensa interação entre os alunos e o professor, e mesmo dos alunos entre si, comentando trabalhos escritos no sentido de pouco a pouco ir desinibindo os alunos em relação à escrita e ir melhorando essa competência o que se verificou tanto na qualidade quanto na quantidade de textos e comentários publicados.

Figura 2. Aspeto parcial de um post.

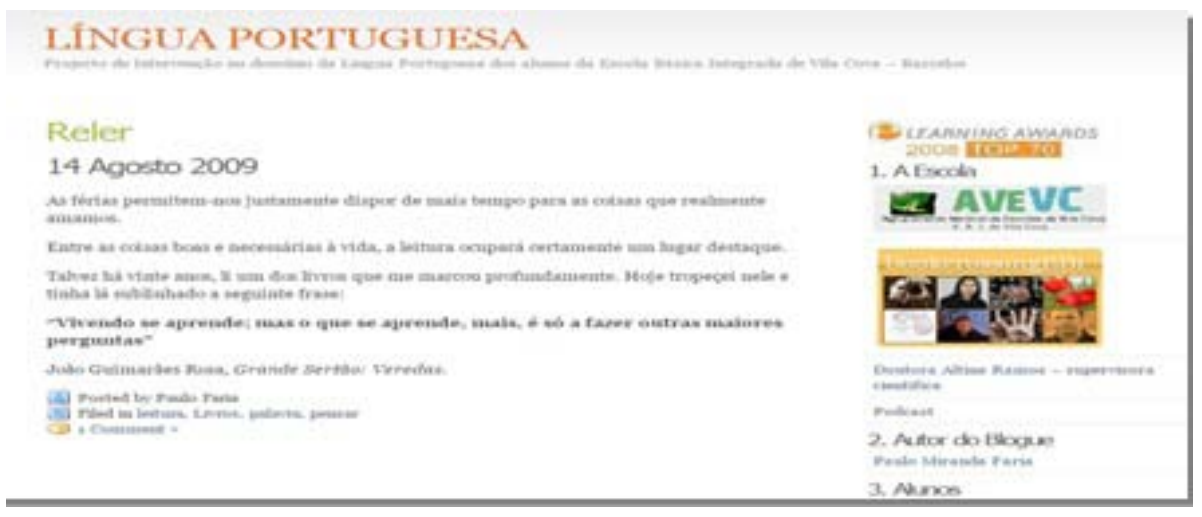

Fonte: https://paulofaria.wordpress.com

O blogue estruturava o seu blogroll em categorias. O destaque está na possibilidade de aceder aos blogues de todos os alunos a partir deste domínio, onde figuram todos os seus nomes por ordem 
alfabética. O blogue incorpora também uma série de ligações que funcionam como ferramentas auxiliares da língua: i) dicionário de sinónimos, de antónimos, de verbos, de termos literários; ii) sítios de divulgação de livros, como blogues temáticos, jornais, Plano Nacional de Leitura, e outros; iii) plataformas virtuais de aprendizagem; iv) sítio da Escola; v) sítios da Web de conteúdo diversificado e de interesse para os alunos.

Poder-se-iam estabelecer quatro grandes áreas, tendo em conta a funcionalidade do blogue ao longo dos três anos da sua existência, a saber: divulgação; projetos/desafios; avaliação; ligações.

Apesar disso, neste artigo serão unicamente apresentadas três atividades que nos parecerem mais ilustrativas do trabalho desenvolvido no campo da leitura.

Os livros da minha vida (2 março 2009)

(https://paulofaria.wordpress.com/2009/03/02/os-livros-da-minha-vida/\#comments)

Na Semana da Leitura, sugiro que cada um escreva algo sobre um livro marcante da sua vida ou transcreva mesmo um pequeno excerto. Estou a escrever este post e penso na dificuldade em escolher esse livro... Acho que vou terminar a leitura de "O Anjo da Tempestade" de Nuno Júdice e já faço um comentário.

Este post teve obteve 27 comentários dos alunos. Cada um selecionava um pequeno excerto do livro que estava a ler e partilhava-o publicamente. Na aula, aprofundava-se os motivos e trocavam-se as experiências de leitura de cada um.

Um projecto a duas mãos (11 dezembro 2008)

(https://paulofaria.wordpress.com/2008/12/11/um-projecto-a-duas-maos/)

Este projeto foi concebido em articulação com a disciplina de Educação Visual. A partir de $O$ Velho e o Mar, Ernest Hemingway - transformámos a palavra em traço e o adjetivo em cor. Através da técnica de xilogravura, os alunos do 9. Ano, Turma $\mathrm{C}$, procuram atributos no livro de Hemingway. A primeira parte do trabalho consistiu em escolher as palavras e a partir daqui visualizar imagens, contextualizando-as com a história do livro. Posteriormente, e depois de os alunos elaborarem vários estudos, realizaram o trabalho final, que gravaram em placas de xilogravura. Por fim, imprimiram os trabalhos e fizeram alguns apontamentos de cor, com tinta acrílica. 


\author{
(https://paulofaria.wordpress.com/2007/10/19/comentario-do-escritor-manuel-jorge- \\ marmelo/)
}

O escritor Jorge Marmelo, à semelhança de outros, interagiu várias vezes com os alunos. Neste caso, não foi possível um contacto presencial, mas sim a distância. Além disso, foi realizada uma sessão skype para a delegação do jornal Público, no Porto. Eis o comentário do escritor Manuel Jorge Marmelo.

(...) Antes de mais, gostava de agradecer a todos a entusiástica resposta ao desafio que aqui lancei.

Fui lendo os vários textos que escreveram e até a mim me surpreendeu o facto de, a partir de um mesmo parágrafo, ter sido possível escrever histórias tão variadas e diferentes umas das outras.

Assim que o professor Paulo Faria entender adequado, ser-vos-á mostrado o conto que eu próprio escrevi a partir daquele mesmo parágrafo. Não para que comparem, mas para que vejam como é possível acrescentar sempre uma versão diferente, dependendo da vivência que temos, das experiências que vamos acumulando com a idade e do treino que temos no manuseio da língua. Se pretenderem ler outros textos meus, podem sempre consultar o meu "site" na internet (http://planeta.ip.pt/ ip202503/marmelo.html).

Quanto à aula de jornalismo que a Andreia propõe: não sou professor. Mas podemos tentar combinar um encontro para conversar sobre estas coisas todas, os livros, o jornalismo, etc.

Um abraço para todos, Jorge.

Iniciado, ainda que de forma experimental, no ano letivo de 2006/07, este projeto teve uma vertente de formação de âmbito técnico e pedagógico, com a supervisão científica do Instituto de Educação da Universidade do Minho. A intenção era conhecer e depois integrar na prática pedagógica do ensino do Português recursos digitais, preferencialmente da Web 2.0. Centrou-se toda a atenção, num primeiro momento formativo, na descoberta e experimentação de recursos digitais que favorecessem primeiro no professor e depois nos alunos a aquisição de novas competências. Pretendia-se explorar e integrar recursos digitais, não como ferramentas produtivas, mas como ferramentas cognitivas, tal como Jonassen (2007) as concebeu. Ao mesmo tempo, o objetivo passava por aproveitar os recursos digitais gratuitos disponíveis na Web, na perspetiva de que o conhecimento deve ser livre e acessível a todos, potenciando espaços colaborativos para a partilha do conhecimento. 
b) Plataforma interativa bookcrossing EBI

Associado a este projeto, coordenamos e dinamizamos outros, como uma rede social NING designada por bookcrossingEBI e que surgiu em 2008 a partir de uma plataforma que visava essencialmente promover a troca e a experiências de leitura. Este era um espaço aberto e por isso contava com professores, alunos, encarregados de educação e pessoas exteriores à escola. Cresceu até próximo dos 800 membros.

Partimos do pressuposto de que uma orientação metodológica que privilegiasse a participação dos professores na construção e na procura de estratégias conducentes à resolução dos problemas, relacionadas com o ensino do Português, teria garantia para ser bem sucedida. Aliás, o trabalho colaborativo, nomeadamente potenciado pelas interações nas redes sociais, como foi exemplo o projeto bookcrossingEBI, relacionado com a promoção do livro e da leitura iniciado em 2008, foi um excelente ensaio para outro projeto iniciado em 2011. Os professores tomavam uma posição procedente, no sentido de assumirem que neste contexto dever-se-ia enfatizar todo trabalho assente na ação - reflexão - partilha. Assumia-se, especificamente, que havia a necessidade de comunicar em registos multimodais que favorecessem o desenvolvimento de novas literacias e aproximassem professores e alunos, porque cada vez mais se constatava que utilizam diferentes formas de comunicar e de produzir sentido, através de uma diversidade de meios digitais. Era essa a grande missão: refletir e depois propor novas formas de abordagem entre o ambiente social em profunda mudança e a urgência de novas políticas pedagógicas reivindicadas pelas novas literacias ou novos formatos multimodais.

Figura 3. Aspeto geral da plataforma bookcrossingEBI.

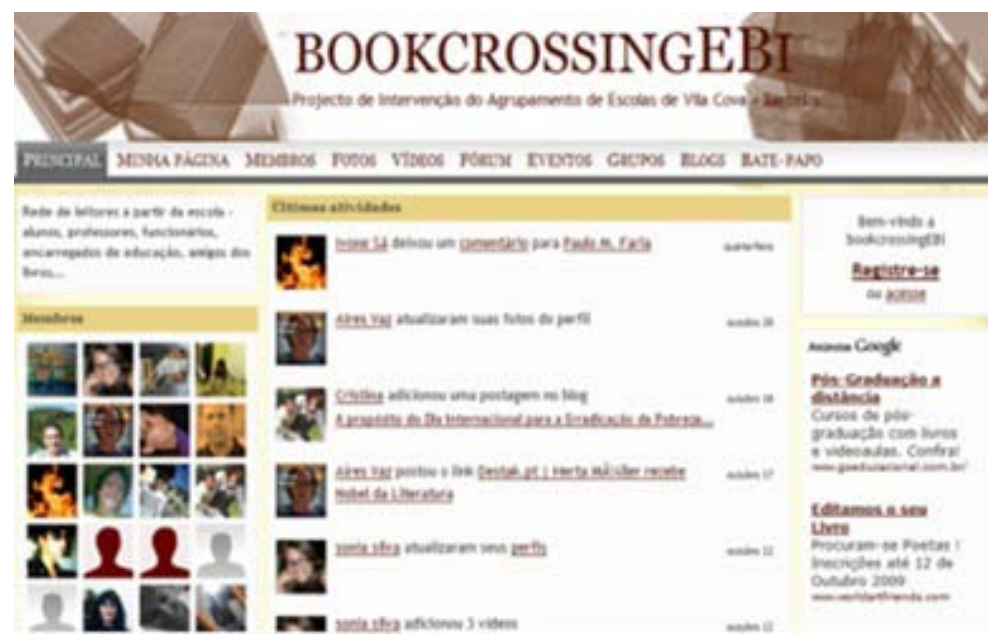

Fonte: https://bookcrossingEBI.com

p/U $a$ i $S$ Salvador, v. 4, n. 2, p. 26-46, mai./ago. 2019 
Embora tivessem coexistido no tempo, o Blogue Lingua Portuguesa e a plataforma bookcrossingEBI, são projetos com fins semelhantes, mas com princípios e estratégias diferentes. A plataforma visava a promoção e divulgação do livro, da leitura, mas não estava orientada pelos princípios programáticos disciplinares ou do currículo. Desde de início, foi concebida como um espaço transversal a todos os atores educativos do Agrupamento - alunos, professores, funcionários, encarregados de educação e amigos dos livros - sem qualquer limitação à sua participação. A ideia primacial que sustentava a iniciativa seria que o instrumento mais importante de que as pessoas devem elevar o seu nível de competência é a leitura. Nesse sentido, proporcionar aos alunos a capacidade crescente de ler o mundo, extraindo gradualmente significados cada vez mais complexos, a partir dos desafios que se renovavam dia a após dia, seria a melhor forma de se inverter o cenário atrás descrito.

Apesar de se acreditar que haveria vantagens em utilizar os recursos digitais para ensinar Português, cedo se percebeu que a existência de novos cenários, linguagens e suportes para o acesso à informação exigiria o domínio de literacias múltiplas, o que consistia numa problemática que ultrapassava questões de acesso aos meios informáticos, cada vez mais disponíveis na escola e na vida de cada um (LIVINGSTONE, 2009). Desta forma, era solicitado a cada dia aos professores o domínio de competências que exigiam não só conhecer novas abordagens técnicas e tecnológicas, como a reconfiguração dos meios de interação, de produção e divulgação da palavra.

Outra intenção mais subtil do Bookcrossing foi construir, ainda que informalmente, um ambiente que aproximou os professores através da partilha de livros e de leituras. A consciência de que todos devem contribuir para aumentar a proficiência leitora dos alunos, passava da letra morta dos decretos para uma prática desenvolvida através desta rede que se configurava num quadro próximo de um verdadeiro ecossistema educativo (DABNER ET AL., 2012). Em boa verdade, seguia-se o pensamento de Nabhani e Bahous (2010) quando sugerem que o trabalho docente seja realizado em rede e entre várias escolas o que contribui para ultrapassar ideias negativas preconcebidas que alguns professores têm em relação às experiências com tecnologias digitais (HIXON ET AL., 2009). Neste âmbito, a experimentação e o contacto pessoal com atividades bem-sucedidas destas comunidades são também fatores favoráveis à formação dos professores para o uso educativo de tecnologias. E este aspeto foi claro no caso dos professores desta escola.

Conclui-se este ponto com uma reflexão do trabalho realizado até ao ano de 2008/09, adiantando que a escola passou por um longo processo de transfiguração por força das dinâmicas sucintamente descritas; os professores e alunos viveram e partilharam experiências 
verdadeiramente enriquecedoras e estimulantes tato a nível académico como social e humano. Ao mesmo tempo, um dado relevante para a comunidade educativa, após três anos da implementação destes projetos, foi o resultado dos exames nacionais do ano letivo de 2008/09, na disciplina de Português do 9. ${ }^{\circ}$ ano: pela primeira vez na história da escola, esta atingiu $74 \%$ de sucesso, contra $70 \%$ a nível nacional. Não atribuímos, de modo algum, a responsabilidade deste sucesso aos projetos aqui referidos. Mas também não podemos deixar de entrever alguma relação entre ambas as realidades.

c) eReaders e ebooks para a comunidade escolar

Apesar da visível melhoria nos resultados a Português, por força de um conjunto de ações que passaram não só pela promoção de hábitos de leitura, mas também pelo aumento da proficiência leitora de textos literários de todas as tipologias, havia a consciência e a vontade de que muito havia a fazer neste domínio.

Havia a ambição de encontrar novas propostas de atuação que passam por discutir e apresentar novas soluções e novos sentidos na utilização das tecnologias digitais. Neste percurso, foi frequentemente necessário alterar procedimentos e sobretudo desconstruir um lugar-comum, muito difundido, que consiste em aceitar que a inovação na educação surge quase sempre aliada à perspetiva de que a tecnologia é um meio para a inovação e que por si mesma a cria. Não é verdade. Não obstante defendermos que os meios digitais são recursos poderosos para incentivar a inovação em contexto educativo, ainda é fundamental repetir que o que muda com a tecnologia está muito para além dela. Era necessário construir uma escola que integre o digital, mas não apenas para desenvolver nos jovens competências instrumentais para o "uso" das tecnologias da informação e da comunicação. Importa é preparar os atuais estudantes para uma pertença cultural plena, madura e ativa na nova era" (FIGUEIREDO, p. 20, 2016). Para isso, foi indispensável construir pensamento, linhas de ação com os professores que os levassem ao uso efetivo de práticas inovadoras com meios digitais.

Figura 4. Utilização de eReaders em contexto de sala

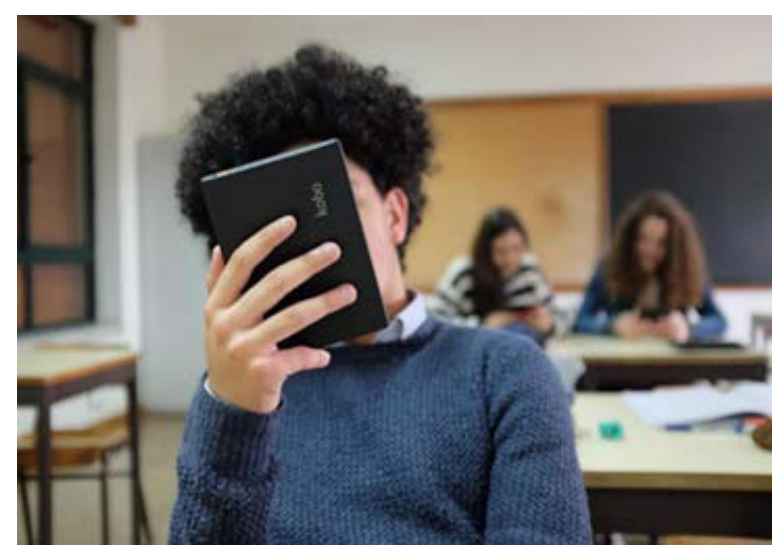

Fonte: Banco de Imagens da ESVC

p/U $a$ ì S Salvador, v. 4, n. 2, p. 26-46, mai./ago. 2019 
Por se tratar de projetos que emergem no seio de um diálogo, a leitura precisava de novas e mais eficientes respostas. Segundo Chartier (2010), estamos a viver o que metaforicamente designa a "terceira revolução do livro". Queremos com isso sugerir que as grandes mudanças de hoje são as transformações mais profundas a que algum dia se assistiu porque as suas implicações fazem-se notar não só nos suportes físicos, com também a forma como circulam os novos livros e a eles se acede ou se partilham.

Considerada então que a competência da leitura necessitaria de um plano de intervenção mais aprofundado, constatou-se que seria adequado desenvolver medidas que incrementassem o uso de dispositivos tecnológicos, especialmente aqueles que cada aluno e cada professor transportam consigo (DAVIS, ET AL., 2009; ROEHRIG, ET AL., 2011; WHITEHEAD, ET AL., 2011; WILLIAMS ET AL., 2007). Nessa perspetiva, defende-se uma lógica de atuação próxima da máxima "bring your own device", (CRAIG ET AL., 2011; DU, ET AL., 2009; RAVENSCROFT, ET AL., 2010) pelo que urge encontrar e redesenhar tarefas e projetos para utilização criativa destes meios digitais.

Implementou-se um programa de formação de âmbito técnico e pedagógico, de modo a que os professores de Português e de Línguas pudessem conhecer e depois integrar na sua prática pedagógica dispositivos móveis, especialmente eReaders. Trabalhamos com diversificação de estratégias de leitura para localizar, selecionar, avaliar e organizar a informação; utilizar adequadamente dispositivos tecnológicos para assegurar uma maior eficácia na comunicação e implementar várias abordagens no desenvolvimento das competências da leitura e do oral. Partiuse de dois pressupostos, um deles, de que um dos mandatos centrais e inalienáveis da escola é a formação de leitores (Duarte, 2013): o outro considera que o espaço natural e emergente do mobile learning desafia a construção de novos e diversificados modelos pedagógicos (NORDIN, ET AL., 2010; PARSONS, ET AL., 2007) e também de novas aproximações à leitura.

Consideramos que os novos suportes para ler, no caso concreto os eReaders, podem trazer inovação e vantagens evidentes para a prática pedagógica, implicando aprendizagens não só ao nível tecnológico e metodológico, mas também no plano relacional com os alunos. O eReader poderá contribuir para a bem-sucedida fusão desses fatores.

A primeira experiência com eReaders ocorreu no ano letivo de 2010/11, e foi financiada pela Fundação Calouste Gulbenkian, no âmbito do projeto de Estímulo da Melhoria das Aprendizagens. Neste momento, com cerca de 60 e-Readers, defende-se que, pelas suas características técnicas, praticamente limitados à sua funcionalidade principal, é possível disponibilizar uma ampla diversidade de textos. Relevante foi os professores salientarem que as suas limitações intrínsecas 
evitavam que os alunos se dispersassem e poderiam ser uma vantagem no desenvolvimento de uma leitura mais profunda que necessita de maior nível de concentração. Também se revelavam dispositivos que facilitadores do acesso táctil aos dicionários de Português ou de outras línguas, estimulando o desenvolvimento do vocabulário dos alunos e enriquecendo a sua competência lexical. Ao mesmo tempo, ampliava e diversificava o campo de propostas didáticas de que o professor poderia dispor.

Em síntese, sistematizou-se um conjunto de vantagens evidenciadas pelo uso dos eReaders, pelos professores e alunos:

- $\quad$ Portabilidade, que se repercute na rentabilização do tempo para ler.

- Capacidade de armazenamento de mais de mil livros e uma autonomia que ultrapassa um mês.

- O tipo de ecrã utilizado, pela sua natureza, é também muito agradável para ler e não tem qualquer tipo de problema em ser utilizado na rua, mesmo com muito sol. O cansaço visual é equivalente ao que temos ao ler um livro em papel.

- É também bastante fácil tirar notas, sublinhar partes interessantes e exportá-las.

- O leitor de e-books permite a leitura de vários livros em paralelo.

- Dispõe-se de um grande acervo de livros gratuitos, pertencentes ao domínio público.

- Possibilidade de comprar um e-book e recebê-lo no momento e em qualquer lugar.

- O dicionário integrado permite ler mais facilmente um livro numa língua estrangeira.

Importa também referir que existe a possibilidade de qualquer membro da escola requisitar um eReader à semelhança de um livro.

d) Da biblioteca à multiplicação de ecrãs

No ano de 2015, no âmbito do concurso à Fundação Montepio, a Escola foi distinguida com um prémio nacional para a categoria inovação, designado por "Leituras com Ciência na era da multiplicação de ecrãs - desafios e oportunidade para professores e alunos". Partia-se também da problemática comum de assumir, como acima referimos, que um dos mandatos centrais da escola é a formação de leitores e o desenvolvimento da sua competência leitora. Temos sempre o intuito de procurar no espaço natural e emergente do mobile learning novos e diversificados modelos de ação pedagógica que atendam particularmente aos novos procedimentos de promoção da 
leitura. Nesse pressuposto, desenharam-se atividades diversificadas de formação de professores conducentes ao incremento da leitura partilhada de obras selecionadas (científicas e outras), a qual deveria proporcionar uma visão multidisciplinar e contribuir para a formação de uma cultura científica mais vasta, geradora de conhecimento científico e de espírito crítico numa perspetiva intergeracional. A decisão de promover, numa escola, a construção de um espaço de aprendizagem com características próximas das "salas de aula do futuro" - pontuadas pela inovação pedagógica promovidos e coordenados nos últimos anos pela European Schoolnet, implicou equacionar e ter em consideração uma variedade de fatores críticos para que as suas potencialidades possam vir a ser plenamente aproveitadas pela escola e para que os riscos sempre inerentes à fase inicial de um projeto possam ser minimizados.

Se seguida, apresentam-se algumas ações neste âmbito.

\section{O acesso aos livros e à leitura}

Na imagem 5, apresentada abaixo, pode testemunhar-se a utilização que os alunos fazem do seu smartphone para leitura de código QR. De salientar que cada um dos códigos, que podem ser decifrados pelos dispositivos digitais móveis dos alunos, possibilita o acesso a imagens, a sítios, a sinopses de obras e a filmes. Houve, pois, a intenção de fomentar o acesso e a promoção ao livro através de uma multiplicidade de meios.

Figura 5. Utilização smartphones para aceder a informação através de QR-code

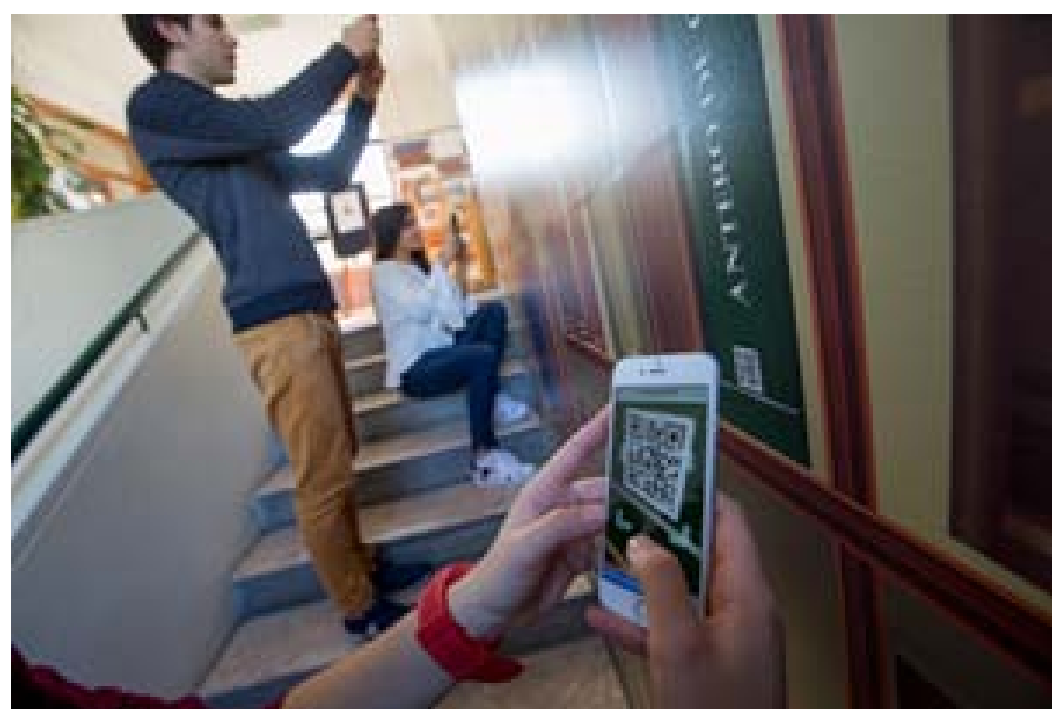

Fonte: Banco de Imagens da ESVC

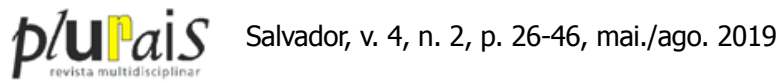




\section{A leitura também pode ser uma atividade social e em rede}

Quisemos construir um espaço visual-virtual que ajudasse a descobrir o livro pela imagem. Uma das ações previstas e planificadas aquando da candidatura deste projeto consistia na dinamização de uma rede a partir do Pinterest. A ideia ganhou ainda mais força e neste momento, depois de terem sido já realizados os primeiros contactos com a direção da escola e com a Câmara Municipal de Barcelos, pretende-se reconstruir o Catálogo da escola e consequente acesso, prioritariamente através da rede e de meios digitais. Para isso, já foram realizadas a construção de alguns catálogos no Pinterest para acesso em vários pontos da escola, logo à entrada da biblioteca através de telas digitais (por exemplo tablets ou outros dispositivos digitais fixos).

Figura 6. Utilização do Pinterest com catálogo

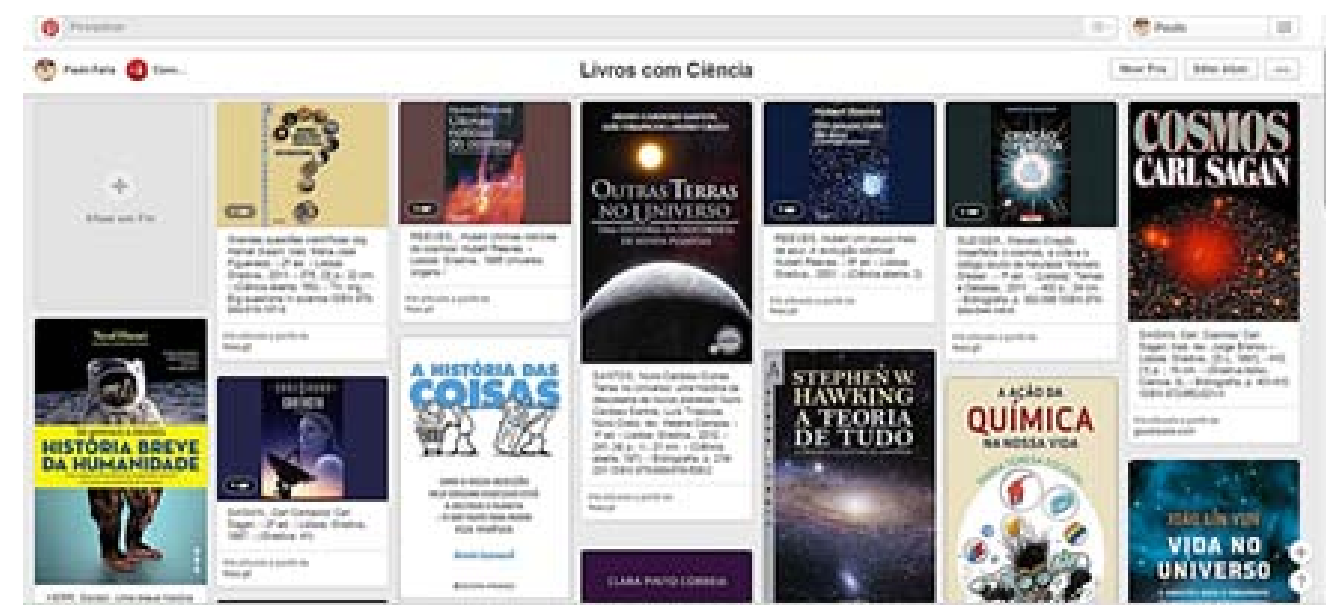

Fonte: Banco de Imagens da ESVC

O exemplo que se apresenta é uma das iniciativas já realizadas, mas que ainda não foi devidamente potenciada junto da comunidade pelas razões evocadas, mas também porque este é um processo lento e que exige tempo para que a comunidade educativa percecione e adira aos novos procedimentos em curso. Trata-se de uma parte do catálogo temático que pode ser acedida por qualquer pessoa e que foi designada de "Livros com ciência". 


\section{Reflexão final}

Durantes este percurso longo, intenso e gratificante, que aqui brevemente descrevemos, dois fatores parecem ficar evidentes: os meios digitais influenciam a competência leitora dos alunos, mas é toda a arquitetura metodológica, didática e científica construídas pelos professores, com a participação ativa dos alunos, a grande responsável pelos pequenos e grandes sucessos que vamos obtendo. Com efeito, os bons resultados, revelam benefícios inerentes aos suportes digitais como incentivos à modificação das atitudes dos professores face às tecnologias (J.-Q. CHEN ET AL., 2006) especialmente, à utilização e de eReaders.

Os novos suportes de leitura trouxeram inovação e vantagens evidentes para as práticas pedagógicas, implicando aprendizagens não só ao nível tecnológico e metodológico, mas também no plano relacional com os alunos. Assim, as tecnologias digitais criam oportunidades de leitura e também na escrita que desafiam as práticas das escolas tradicionais (COLLINS ET AL., 2010) para uma nova realidade ancorada numa ecologia de aprendizagem - como define Barron (2006) onde $o$ ato de aprender acontece cada vez mais em contextos informais. Cremos que educar não é especular através de dilemas e receios se o livro em suporte de papel está a ser substituído. Chartier (2010) utiliza metaforicamente a expressão terceira revolução do livro para designar as grandes mudanças a que assistimos hoje. Segundo o autor, são as transformações mais profundas a que algum dia se assistiu porque as implicações fazem-se notar não só nos suportes físicos, com também a forma como se acede aos novos livros, como circulam e se partilham. Dos quatro elementos primordiais, provavelmente é na nuvem digital onde mais hoje se lê, ainda que devam coexistir todos os outros suportes. A "sala de leituras do futuro" representa acima de tudo, mais que um espaço, a confluência de vontades, sobretudo para contribuir para ler cada vez melhor o mundo.

Por fim, um dado que trouxe à comunidade educativa um grande regozijo na avaliação não só destes projetos individuais: no ano de 2015/16, esta escola ficou colocada em primeiro lugar no ranking nacional no que diz respeito ao índice da promoção do sucesso, o que de algum modo valida toda uma política que se seguiu, mas também nos responsabiliza por continuar os caminhos traçados.

Em síntese, estes projetos e atividades revelaram-se como um conjunto importante de competências transversais essenciais à vida no século XXI. Cremos que os princípios pedagógicos da escola atual se devem nortear por uma visão interdisciplinar de articulação com o currículo e interdependente do conhecimento, através de projetos que contemplem uma aprendizagem que vai para além do desenvolvimento de conhecimentos e competências ao nível cognitivo, mas que 
envolva simultaneamente as competências essenciais para a vida na sociedade, nos domínios linguístico, social, artístico e emocional. A leitura literária pode ser a chave para a reconstrução do novo mundo.

\section{REFERÊNCIAS}

BARRON, B. Interest and self-sustained learning as catalysts of development: A learning ecology perspective. Human development, 49(4), 193-224. 2006.

COLLINS, A., \& Halverson, R. The second educational revolution: rethinking education in the age of technology. Journal of Computer Assisted Learning, 26(1), 18-27. 2010.

DAVIS, N., Preston, C., \& Sahin, I. Training teachers to use new technologies impacts multiple ecologies: Evidence from a national initiative. British Journal of Educational Technology, 40(5), 861-878. doi: 10.1111/j.1467-8535.2008.00875.x. 2009.

CHARTIER, R. Escutar os mortos com os olhos. estudos avançados, 24(69), 6-30. 2010.

DABNER, N., Davis, N., \& Zaka, P. Authentic Project-Based Design of Professional Development for Teachers Studying Online and Blended Teaching. Contemporary Issues in Technology and Teacher Education, 12(1), 71-114. 2012.

DUARTE, R. Ensino da literatura: nós e laços. Doutoramento, Universidade do Minho, Braga. 2013.

FIGUEIREDO, A. Por uma escola com futuro ... para além do digital. Revista Nova Ágora, $\mathrm{n}^{\circ}$ 5, Set. pp. 19-21. 2016.

GOMES, M. J. "Blogs: um recurso e uma estratégia pedagógica". In A. Mendes, I, Pereira e R. Costa (Eds.), Actas do VII Simpósio Internacional de Informática Educativa, ( pp.311-315). Leiria: Escola Superior de Educação de Leiria. 2005.

GRANIERI, G. Geração Blogue. Lisboa: Presença. 2006.

HIXON, E., \& Buckenmeyer, J. Revisiting technology integration in schools: Implications for professional development. Computers in the Schools, 26(2), 130-146. 2009.

JONASSEN, D. Computadores, Ferramentas Cognitivas. Desenvolver o pensamento crítico nas escolas. Porto: Porto Editora, 2007. 
LIVINGSTONE, S. Risky experiences for children online: charting European research on children and the Internet. . Children and Society, 22 (4), pp. 314-323. 2008.

NORDIN, N., Embi, M. A., \& Yunus, M. M. Mobile learning framework for lifelong learning. Procedia-Social and Behavioral Sciences, 7, 130-138. 2010.

PARSONS, D., Ryu, H., \& Cranshaw, M. A design requirements framework for mobile learning environments. Journal of Computers, 2(4), 1-8. 2007.

RAVENSCROFT, A., \& Boyle, T. A Dialogue and Social Software Perspective on Deep Learning Design. Journal of Interactive Media in Education. 2010.

ROEHRIG, G. H., Dubosarsky, M., Mason, A., Carlson, S., \& Murphy, B. We Look More, Listen More, Notice More: Impact of Sustained Professional Development on Head Start Teachers' Inquiry-Based and Culturally-Relevant Science Teaching Practices. Journal of Science Education and Technology, 20(5), 566-578. 2011.

WHITEHEAD, L. C., Rudick, S., \& South, K. High Tech, High Touch: An Innovative Approach to Professional Development for CDA Candidates. Young Children, 66(3), 48-50. 2011.

WILLIAMS, D., \& Coles, L. Teachers' Approaches to Finding and Using Research Evidence: An Information Literacy Perspective. Educational Research, 49(2), 185-206. 2007.

WARSCHAUER, M., \& Matuchniak, T. Nova Tecnologia e Mundos Digitais: Analisando Evidências de Equidade no Acesso, Uso e Resultados. Revisão da Pesquisa em Educação , 34(1), 179-25.https://doi.org/10.3102/0091732X09349791. 2010.

Enviado em: 22 de julho de 2019

Apreciado em: 30 de julho de 2019

Inserido em: 01 de agosto de 2019 